[Agr. Biol. Chem., Vol. 31, No. 4, p. 507 510, 1967]

\title{
Ultraviolet Optical Rotatory Dispersion of
}

\section{Aspergillopeptidase A}

Sir:

In a previous paper, ${ }^{1 /}$ it was reported from the optical rotatory dispersion in the visible and near ultraviolet regions over 320 to $600 \mathrm{~m} \mu$ that the acid proteinase of Aspergillus saitoi (aspergillopeptidase A, EC, 3.4.4.17) (2) $^{2 \sim}$ has the optical rotation, $[\alpha]_{\mathrm{D}}$, of $-35^{\circ}$, the optical rotatory dispersion constant, $\lambda_{c}$, of $207 \mathrm{~m} \mu$, and the values of $-a_{0}=211$ and $-b_{0}=0$ in the Moffitt-Yang parameters. The location of an amide I band at $1632 \mathrm{~cm}^{-1}$ was observed in the infrared spectrum of the deuterium-exchanged aspergillopeptidase A. ${ }^{11}$ This result suggested that the enzyme contains the antiparallel $\beta$ structure. ${ }^{5,61}$

In this communication, an attempt has been made to clarify the internal structure of aspergillopeptidase $\mathrm{A}$ in aqueous solution using the optical rotatory dispersion in the deep ultraviolet region. The internal structure of other proteinases is compared and discussed.

Aspergillopeptidase A purified according to the previous method ${ }^{23}$ was further purified on Sephadex G-100 at $\mathrm{pH} 4.0$ for the separation of minor autodigestive products and lyophilized. Twice crystallized pepsin (EC, 3.4.4.1), No. 34046, was obtained from General Bio-

1) E. Ichishima and F. Yoshida, Biochim. Biophys. Acta, 128, 130 (1966).

2) E. Ichishima and F. Yoshida, ibid., 99, 360 (1965).

3) E. Ichishima and F. Yoshida, Nature, 207, 525 (1965).

4) E. Ichishima and F. Yoshida, Biochim. Biophys. Acta, 110, 155 (1965).

5) K. Imahori, Biopolymers, 1, 563 (1963).

6) S. Timasheff and H. Susi, J.Biol. Chem., 241, $249(1966)$ chemicals Inc., U.S. A. The mean residue molecular weight of pepsin was calculated as 101.8 from the experimental data of Rajagopalan et al." The crystalline preparation of Aspergillus oryzae alkaline proteinase ${ }^{81}$ (aspergillopeptidase B, kindly supplied from Dr. W. C. Crewther) was further purified by gel filtration of Sephadex G-100 at pH 7.0 and lyophilized. The mean residue molecular weight of aspergillopeptidase B was calculated to be 104.7 from the experimental data of Subramanian and Kalnitsky. ${ }^{9}$ Crystalline Bacillus subtilis proteinase (subtilopeptidase A, EC, 3.4.4.16) was purchased from Nagase Co. The mean residue molecular weight of subtilopeptidase A employed was 103.6. The optical rotatory dispersion measurements of aspergillopeptidase B and sultilopeptidase A were made at $\mathrm{pH}$ 5.5.

The optical rotatory dispersion measurements were made in the 195 to $250 \mathrm{~m} \mu$ wave length region with a Japan Spectroscopic model ORD/UV-5 recording polarimeter at room temperature of 22 to $25^{\circ} \mathrm{C}$. All measurements were made in optical quartz cell with an optical path of $1.0 \mathrm{~mm}$. The results obtained in the 195 to $210 \mathrm{~m} \mu$ zone were checked under an anaerobic condition that the nitrogen gas was delivered to the cell chamber at a slightly positive pressure. The protein concentration was $0.09 \%$ in $0.01 \mathrm{~m}$ citrate buf-

7) R. C. Williams, Jr, and T. G. Rajagopalan et al., J. Biol. Chem., 241, 4940, 4951 (1966).

8) W. C. Crewther and F. G. Lennox, Nature, 165, $680(1950)$

9) A. R. Subramanian and G. Kalnitsky, Biochemistry, 3, 1861, 1868 (1964). 
fer, $\mathrm{pH} 5.5$, at 212 to $250 \mathrm{~m} \mu$ spectral zone, and it was 0.030 to $0.0075 \%$ at 195 to $210 \mathrm{~m} \mu$. Further dilutions of the initial solution of $0.09 \%$ were made with $0.001 \mathrm{M}$ citrate buffer, $\mathrm{pH}$ 5.5. The corrected specific rotation $\left[\mathrm{m}^{\prime}\right]$ values $^{201}$ were computed from the relationship

$$
\left[m^{\prime}\right]=[\alpha] \frac{3}{n^{2}+2} \frac{M_{0}}{100}
$$

where $[\alpha]$ is the specific rotation and $n$ is the refractive index of the solvent. The refractivc index value of water ${ }^{11}$ was also used for the dilued buffer solutions. The mean residue molecular weight $\left(M_{0}\right)$ of aspergillopeptidase A was calculated to be 106.0 from amino acid composition of aspergillopeptidase A. " All points on the curves $(195 \sim 250 \mathrm{~m} \mu)$ represent average values of measurements.

The curve in the Fig. 1 shows the optical rotatory dispersion of aqueous aspergilloptidase A. At the condition of $\mathrm{pH} 5.5,22$ to $25^{\circ} \mathrm{C}$, autodigestion of aspergillopeptidase $\mathrm{A}$ was found to be near zero. The curve of native aspergillopeptidase $\mathrm{A}$ in the Fig. 1 differs strongly from the other curves of the partially $\alpha$-helical proteins, which have a minimum at $233 \mathrm{~m} \mu$ and a high positive maximum at $198 \mathrm{~m} \mu{ }^{12}$ The negative minimum of the

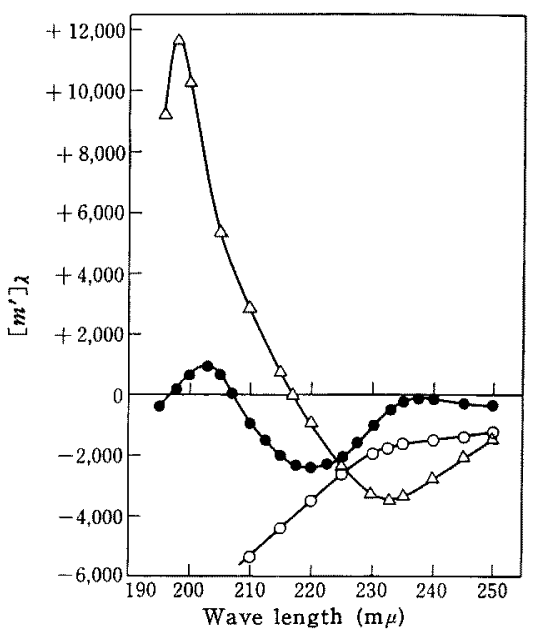

FIG. 1. Ultraviolet Optical Rotatory Dispersion of Aspergillopeptidase A.

The concentration of the enzyme was 0.09 to $0.0075 \%$ at $\mathrm{pH} 5.5,22$ to $25^{\circ} \mathrm{C}$. The thickness of solution layer was $1 \mathrm{~mm}$ in 195 to $250 \mathrm{m \mu}$ spectral zone. The mean residue molecular weight of 106.0 was employed. native aspergillopeptidase A; $\triangle \longrightarrow \triangle$, aspergillopeptidase $A$ with $0.02 \mathrm{M}$ sodium lauryl sulfate; $\bigcirc-O$, aspergillopeptidase $A$ with $8 \mathrm{M}$ urea.

Cotton effect of aspergillopeptidase $\mathrm{A}$ was not at $233 \mathrm{~m} \mu$ but at $220 \mathrm{~m} \mu$. The $\left[m^{\prime}\right]_{220}$ value of the negative Cotton effect was found to be

TABle I. Ultraviolet Optical Rotatory DisPersion of AsPergillopeptidase A AND Other Proteinases IN 195 to $250 \mathrm{~m} \mu$ ZoNe.

\begin{tabular}{|c|c|c|c|c|c|}
\hline \multirow{3}{*}{ Enzyme } & \multirow{2}{*}{\multicolumn{2}{|c|}{ ORD-Trough }} & \multirow{2}{*}{\multicolumn{2}{|c|}{$\frac{\text { ORD-Peak }}{\text { Position }\left[m^{\prime}\right]}$}} & \multirow{3}{*}{$\begin{array}{c}\text { Cross-over } \\
\text { wave length } \\
(\mathrm{m} \mu)\end{array}$} \\
\hline & & & & & \\
\hline & $(\mathrm{m} \widetilde{\mu})$ & $\min$. & $(\mathrm{m} \mu)$ & $\overline{\max }$. & \\
\hline Aspergillopeptidase A & 220 & -2400 & 203 & +900 & 270 \\
\hline Pepsin & 226 & -2800 & 203 & +4500 & $214 \sim 215$ \\
\hline Chymotrypsinogen $A^{*}$ & 221 & -5200 & 190 & +14000 & 205 \\
\hline Trypsin* & 224 & -3100 & 203 & +3500 & - \\
\hline Aspergillopeptidase B & 234 & -1400 & 198 & +4900 & 225 \\
\hline Subtilopeptidase A & 232 & -2500 & 198 & +5000 & 220 \\
\hline
\end{tabular}

10) G. D. Fasman, in S. P. Colowick and N. O. Kaplan, "Methods in Enzymology", Vol. 6, Academic Press, New York, U. S. A. (1963) p. 928.

1I) D. Fukushima, Cereal Chem., in press.

12) B. Jirgensons, J. Biol. Chem., 240, 1064 (1965), 241, 147, 4855 (1966). 
$-2400 \pm 150$ (Table I). This curve has a flat peak at $203 \mathrm{~m} \mu$, and the $\left[\mathrm{m}^{\prime}\right]_{199}$ of aspergillopeptidase $\mathrm{A}$ is close to zero. Upon treatment with $0.02 \mathrm{M}$ sodium lauryl sulfate at $22 \pm 2^{\circ} \mathrm{C}$ for $15 \mathrm{~h}$, which has been found as the specific inhibitor of aspergillopeptidase $\mathrm{A},{ }^{131}$ the negative minimum was shifted to $233 \mathrm{~m} \mu$, and the amplitude of the negative Cotton effect was increased (Fig. 1). The $\left[\mathrm{m}^{\prime}\right]_{233}$ and $\left[m^{\prime}\right]_{198}$ values were found as -3400 and +11600 , respectively. The conformation of aspergillopeptidase A was converted by the anionic detergent into partially $\alpha$-helical conformation, as judged from the ultraviolet optical rotatory dispersion curve. The similar conformational transition by the detergent had been observed with chymotrypsinogen A, trypsin, soybean trypsin inhibitor and alcohol dehydrogenase. ${ }^{121}$

According to the previous paper, ${ }^{11}$ the $-a_{0}$ value in the Moffitt-Yang parameter or levorotation of the aspergillopeptidase A molecule increased markedly in the presence of urea, while the value of $b_{0}$ remained unchanged. The specific rotation and the intrinsic viscosity were $-35^{\circ}$ and $0.032 \mathrm{dl} / \mathrm{g}$, respectively. ${ }^{\prime \prime}$ The decrease in the enzymatic activity of aspergillopeptidase $\mathrm{A}$ as a function of urea concentration was observed to be paralleled with the behavior of the $-a_{0}$ value. $^{1 !}$ These findings suggest that the aspergillopeptidase A is completely folded, and is devoid of $\alpha^{-}$ helical conformation. ${ }^{1}$ With $8 \mathrm{M}$ urea at $\mathrm{pH}$ $5.5,22^{\circ} \mathrm{C}$, for $1 \mathrm{~h}$, it was confirmed that the optical rotatory dispersion curve in the deep ultraviolet region was shifted to that of the randomly coiled form ${ }^{12}$ (Fig. 1). It was concluded that the aspergillopeptidase $\mathrm{A}$ is devoid of complete $\alpha$-helical strand, as judged from the ultraviolet optical rotatory dispersion curve at 233 and $198 \mathrm{~m} \mu$.

From the data of Jirgensons ${ }^{121}$ and Raval, ${ }^{141}$

13) F. Yoshida and M. Nagasawa, Bull. Agr. Chem. Soc., 20, 257 (1956).

14) D. N. Raval and J. A. Schellman, Biochim. Biophys. Acta, 107, 463 (1965). the optical rotatory dispersions of chymotrypsinogen A, chymotrypsin (EC, 3.4.4.5), trypsin $(\mathrm{EC}, 3.4 .4 .4)$, rennin $(\mathrm{EC}, 3.4 .4 .3)$ and pepsin are similar to that of aspergillopeptidase $\mathrm{A}$ in the negative Cotton effect of 215 to $225 \mathrm{~m} \mu$ spectral zone. The dispersion curves of these proteinases differ strongly not only from the curve of the $\alpha$-helical type of proteins (myoglobin, serum albumin $)^{121}$ but also from the curve of disordered random chain (phosvitin, ${ }^{12,151}$ disordered poly- $\alpha$-L-glutamic acid. $)^{121}$ The curves of these proteinases have shallow minima at 215 to $225 \mathrm{~m} \mu$ and relatively flat maxima at 200 to $205 .{ }^{12)}$ All of these proteinases have been shown as acid-stable proteinases. ${ }^{16 !}$ The rotatory dispersion at $220 \mathrm{~m} \mu$ of chymotrypsin and trypsin was similar to that of $\gamma$-globulin, in which the existence of the antiparallel $\beta$ structure had been identified by infrared spectrum. ${ }^{51}$ But, the curve of $\gamma$ globulin differs from all others in its positive maximum at $210 \mathrm{~m} \mu^{121}$ The previous result in the infrared spectrum ${ }^{11}$ suggests that the aspergillopeptidase $\mathrm{A}$ contains the antiparallel $\beta$ structure. ${ }^{5,6)}$ But the content of the $\beta$ structure of aspergillopeptidase $A$ is still obscure. In spite of these findings, it is still obscure whether the internal structure of aspergillopeptidase $A$ is characterized by a mixed conformation of the antiparallel $\beta$ structure and the randomly coiled form, or by some kind of ordered structures containing the antiparallel $\beta$ structure. On the contrary, aspergillopeptidase B and subtilopeptidase A have been shown proteolytic enzyme activities like those of chymotrypsin. But the two proteinases have no acid-stability. In the Table I, the optical rotatory dispersions of the two are compared with those of the acid-stable proteinases. The curves of the two proteinases have a definite minimum at about $233 \mathrm{~m} \mu$ and a maximum at $198 \mathrm{~m} \mu$ character-

15) G. E. Perlmann and S. E. Allerton, Nature, 211, 1089 (1966).

16) P. D. Boyer et al. edt., "The Enzymes" Vol. 4, Academic Press, New York, U.S. A. (1960). 
istics of the $\alpha$-helix.

The amino acid compositions, molecular sizes and catalytic functions of these acidstable proteinases are not similar, but these proteinases have the similar characteristic property of acid-stability. ${ }^{16}$ However, a detailed interpretation of the acid-stability is impossible without further study. It is assumed that the characteristic property of acid-stability partially depends on the polypeptide-chain backborn conformation.

We thank Prof. K. Imahori, Prof. B. Maruo and Prof. K. Arima, the University of Tokyo, and Dr. D. Fukushima for their helpful suggestions and valuable discussion.

Eiji ICHISHIMa

Fumihiko Yoshida

Enzymology Laboratory,

Central Research Institute,

Kikkoman Shoyu Co.,

Noda, Chiba-prefecture,

Japan:

Received February 2, 1967 